\title{
Desplazamientos, fronteras, memoria: Bernal Díaz del Castillo y el viaje a las Hibueras
}

\begin{abstract}
Valeria Añón
Este trabajo aborda el relato del viaje a las Hibueras que Bernal Díaz del Castillo presenta en su Historia verdadera de la conquista de la Nueva España entendiéndolo como texto cuya indefinición genérica cruza la memoria, la autobiografía, el viaje, la autofiguración. Leemos entonces las estrategias escriturarias por las cuales el relato de este desplazamiento redefine las variables y dinámicas de la exploración, la conquista y la aprehensión de sujetos y espacios otros.

In this article, we analyze the two years journey to the Hibueras, as narrated by the chronicler Bernal Díaz del Castillo in his True History of the Conquest of New Spain (Historia verdadera de la conquista de la Nueva España). We argue that this narration combines memories, autobiography and self representation. Therefore, we point out the strategies that organize the text and redefine, in a different way, exploration, conquest, and representation of the other.
\end{abstract}



Valeria Añón

Universidad de Buenos Aires

Desplazamientos, fronteras, memoria: Bernal Díaz del Castillo y el viaje a las Hibueras

\section{Introducción}

Antes que la estancia sedentaria, el viaje -el derrotero, la exploración, la migración, el éxodo- se halla en el fundamento mismo del mundo amerindio y también en sus metamorfosis. [...] El viaje participa, a veces dichosamente y casi siempre con duelo, de la razón de ser de América.

Jorge Monteleone, El relato de viaje

Con esta afirmación, que prologa una recopilación de textos sobre imágenes de América, Jorge Monteleone articula los orígenes del Nuevo Mundo en relación con el viaje, antes incluso de que el 'descubrimiento' o la 'conquista' tuvieran lugar. ${ }^{1} \mathrm{La}$ definición misma de lo americano se vincula a los desplazamientos, las migraciones y las fronteras, complejos conceptos que, a comienzos del presente siglo, no dejan de ser revisados por la crítica - aunque, en general, respecto de los viajeros

${ }^{1}$ Monteleone 1998, 147. 
del siglo XIX en adelante, es decir, desde el viaje romántico, y en consonancia con cierta idea del fin del viaje, atravesado por nuevos fenómenos como el turismo- ${ }^{2}$

Es sabido, además, que los textos que están en la base del corpus sobre el Nuevo Mundo son los diarios de Colón; fundadores de representaciones configuradas en un imaginario medieval occidental a partir del cual se proyectan. ${ }^{3}$ Entonces, hablar del espacio americano es referir viajes, tránsitos y derroteros, la experiencia del encuentro con la novedad y, en especial, de su relato en tanto "formación discursiva", ${ }^{4}$ que conforma buena parte del archivo americano. ${ }^{5}$ Así, lo que delimita dicho espacio es el desplazamiento vinculado a la pregunta por la identidad, y la incidencia (simbólica y fáctica) del saber

${ }^{2}$ Respecto de las nociones de "desplazamiento" y "migración”, este trabajo se enmarca en la perspectiva propuesta por Beatriz Colombi en Viaje intelectual. Migraciones y desplazamientos en América Latina (1880-1915), donde, más que acentuar las diferencias o polémicas entre las nociones de exilio, diáspora, inmigración, migración, viaje, etcétera, adopta un "concepto más complejo, [el del] viaje-desplazamiento" (Colombi 2004, 15). Respecto de la noción de "frontera", sigo la propuesta de Elena Altuna, quien las define como "lugares donde entran en contacto cuerpos, ideologías, visiones de mundo, lenguas y no meramente espacios geográficos", en una lectura vinculada a la noción de "zona de contacto" planteada por Mary Louise Pratt (Altuna 2004, 14).

${ }^{3}$ Incluso Miguel Guerin en su conocido artículo "El relato de viaje americano y la redefinición sociocultural de la ecumene europea”, y Margarita Pierini en "La mirada y el discurso: la literatura de viajes" comienzan sus trabajos con estas referencias. De hecho, Pierini aclara que: "la literatura de América se abre con un libro de viajes, el Diario de Colón [...], texto fundador en tantos sentidos y que lo es, también, respecto al género viajes. En él encontramos ya una serie de constantes que se proyectan a través de los siglos y que pueden servir para caracterizar al viajero que llega a tierras americanas" (Pierini 1994, 163). No obstante, este trabajo busca subrayar los deslizamientos y las variantes antes que las constantes, porque es nuestra hipótesis que la contradictoria experiencia de la modernidad permea los relatos de los viajes a América y puede leerse en ellos.

${ }^{4}$ Said 1995.

5 Trabajo, por supuesto, con la noción de archivo definida por Michel Foucault en Arqueología del saber, quien lo entiende como forma moderna del mito, ligada en su origen al discurso legal del poderoso. En términos de revelación y develación, no sólo de un andamiaje ideológico sino también de intertextualidades y sentidos soterrados, es que concibo el texto que se analizará aquí. En este marco, el archivo americano se construiría en el cruce entre el viaje y el encuentro con el 
sobre el otro que, en la mayoría de los casos, define las posibilidades de la conquista.

Todo viaje involucra a los sujetos que lo protagonizan y a quienes lo narran, así como la evaluación de sus resultados respecto de las expectativas iniciales. Estos relatos del mundo americano también pueden ser los de un desplazamiento fracasado, expediciones que no han encontrado oro, riquezas ni grandes civilizaciones sino que, por el contrario, se han visto enfrentadas a la ineludible crueldad de la naturaleza americana, otro tópico en la descripción del Nuevo Mundo que no por reiterado deja de tener un enorme peso en los testimonios de capitanes y soldados. Por otra parte, en el juego de metáforas que el género posibilita, se destaca la escritura como viaje, deslizamiento que también involucra la traslación y la traducción, definidas por saberes heterogéneos, experiencias propias y ajenas, impresiones que trazan profusas redes de diálogo, polémica y comunicación.

Así, en la Historia verdadera de la conquista de la Nueva España de Bernal Díaz del Castillo (texto que nos ocupará aquí; en adelante citada como HV), el relato de la fallida expedición a las Hibueras permite dar cuenta de la constitución escrituraria de un mapa, un nuevo sentido que se produce en la conjunción de las concepciones occidentales y la experiencia americana, cuyas resistencias afectan a la representabilidad de la palabra escrita. ${ }^{6}$ En el lapso que media del clímax de la HV a sus capítulos finales, en el desplazamiento textual que ello implica, es posible leer la necesidad de aprender nuevamente a narrar, esta vez el fracaso. El análisis del relato de Bernal

otro, esa "épica de la alteridad" (Monteleone 1998, 148) inseparable de la pregunta acerca de la identidad.

6 Trabajamos con la edición de la Historia verdadera de la conquista de la Nueva España realizada por José Barbón Rodríguez quien, a diferencia del trabajo del padre Carmelo Sáenz de Santa María, fija y analiza el Manuscrito Guatemala (como se sabe, el texto en el que siguió trabajando Bernal Díaz hasta su muerte). Todas las citas se harán por esta edición. 
Díaz permite reconocer tensiones y luchas por el poder y evidencia las variaciones en la percepción del mundo indígena, entendiendo los resultados de la conquista en una gradación que va de la exaltación a la pérdida, del asombro a la decepción, del 'encuentro' al reclamo y la autolegitimación. En estos intersticios se leerá la variable constitución identitaria que delinea adscripciones, lealtades y críticas, en un movimiento textual que, lejos de ser unívoco, se modifica a lo largo de los capítulos. Entonces, las "zonas de contacto", 7 pasan a ser lugares buscados, de salvación, transformando la dinámica de la exploración y la conquista. ${ }^{8}$

\section{El discurso $^{9}$}

Así como las fronteras del espacio americano son porosas, también lo son los límites del género aquí aludido, siempre en el entrecruzamiento entre el desplazamiento, la memoria y la autobiografía. Lo que define al relato de viaje es su indefinición: complejo, contradictorio en cuanto a su inscripción genérica,

7 Pratt 1997, 11.

${ }^{8}$ Agradezco a Elena Altuna el haberme llamado la atención sobre estas transformaciones, durante las XX Jornadas de Investigación del Instituto de Literatura Hispanoamericana de la Facultad de Filosofía y Letras de la Universidad de Buenos Aires, realizadas en Buenos Aires en noviembre de 2005.

9 El ordenamiento de los próximos apartados — "el discurso", "escritores y viajeros", "el espacio"- - surge de la lectura del citado texto de Margarita Pierini, quien organiza su exposición siguiendo dos ejes, "la mirada" y "el discurso", que caracterizarían la literatura de viajes, con sus inflexiones, entre los siglos XVIII y XIX. Siguiendo dichas sugerencias, en este trabajo se pensaron tres apartados. El primero organiza las reflexiones respecto de la HV como relato de viaje, en la encrucijada con la crónica y la historia; el segundo analiza las representaciones y desplazamientos del yo (narrador y protagonista) en relación con una figura central para la definición identitaria, la del capitán Cortés. Por último, "el espacio" incluye reflexiones sobre las diversas caracterizaciones del derrotero por el sur de México, Guatemala y Honduras (las Hibueras), en el cruce con los dos ejes antes descritos. Asimismo, para leer estos capítulos seguimos y ampliamos varias de las líneas planteadas por María Christen Florencia en su destacado artículo "El viaje a las tinieblas. La expedición a las Hibueras según Bernal Díaz del Castillo”. 
variable diacrónicamente, capaz de incluir diversos tipos discursivos y textuales, tensionado entre ficción y factualidad, experiencia y escritura, verdad y verosimilitud, pareciera resistirse a los límites fijos. Más aún, en tanto relato de un desplazamiento (ya sea virtual o real, exploración, migración, exilio e incluso derrotero turístico) pareciera compartir con su referente cierta expansión de los límites — esperables e incluso concebibles - de la textualidad. Aún a riesgo de caer en el anacronismo, entiendo que el relato de viaje es, en su definición, un tipo textual siempre "fuera de lugar", es decir, descentrado, a caballo entre géneros, épocas, narradores e intencionalidades. $^{10}$

Lo que caracterizaría los capítulos sobre el viaje a las Hibueras en la HV es el relato del desplazamiento, el énfasis en la experiencia y en la verdad de lo contado, y la referencia permanente al transitar, en constante cruce con el relato histórico. ${ }^{11}$ Además, y como elemento común a los relatos de viaje coloniales del siglo XVI (tanto a los textos que pueden englobarse por completo en dicha categoría como a las secciones incluidas en el cuerpo mayor de una crónica o relación, tal

10 Edward Said titula de este modo, Fuera de lugar, su autobiografía, definiéndose a sí mismo a partir de esta tensión e incomodidad que fue persiguiendo, teóricamente, en todos sus escritos, desde Orientalismo hasta Cultura e imperialismo, pasando, por ejemplo, por la peculiar lectura que hace de Mimesis a partir de la situación de exilio en Estambul que hizo posible esta investigación; situación explicitada por Auerbach en el epílogo del famoso estudio y analizada con maestría por Said en su introducción a El mundo, el texto y el crítico. (Agradezco a Leonardo Funes el haberme indicado esta lectura en especial, a propósito de mis investigaciones.)

11 Blanca López de Mariscal señala que estos viajeros inician "su acercamiento a las nuevas tierras mediante una especie de ritual de posesión, que implica una serie de pasos, codificados de antemano". Esos pasos son: transitar, poner nombre y tomar posesión. El primero, "marcador semántico omnipresente [...] implica la referencia constante al trayecto o recorrido [...] que suele ir acompañado por marcadores temporales [...] de tal forma que se percibe al mismo tiempo el tránsito en el tiempo y en el espacio" (López de Mariscal 2004, 81). No obstante, en las Hibueras, este tránsito dificultoso pareciera estar detenido y contraponer, la mayor parte de las veces, las coordenadas espacio-tiempo, de manera que establecerían una relación antagónica antes que complementaria. 
como ocurre con la HV o con las Cartas de Relación de Hernán Cortés), se presenta la experiencia corporal del Nuevo Mundo, el enfrentamiento — muchas veces brutal- con la novedad, y el tesonero impulso de dar cuenta por escrito de estas vivencias.

$\mathrm{Si}$, según Elena Altuna, el relato de viaje es un texto de frontera, entendida como "zona en que ambos espacios entran en contacto", ${ }^{12}$ el relato del viaje a las Hibueras en la HV cultiva esta característica textual para presentar el dilema de una frontera en constante movimiento, "zona de contacto" de problemática relación con el espacio otro. Esta alteridad topográfica obliga a reevaluar las propias capacidades, las escalas de valor, el rango de lo deseable, incluso la propia función dentro de la expedición. Por eso, la entereza de Cortés se desdibuja a medida que la expedición transcurre, y se presentan elementos casi ausentes durante la primera parte de la HV: dudas, padecimientos físicos del capitán y enfermedades que lo llevan casi a la muerte, un ánimo melancólico y taciturno y cierta inquietud acentuada por la sensación de estar moviéndose siempre hacia ninguna parte, o hacia un lugar donde la desgracia no tiene límite. Claro, el recorrido, y el forzamiento y la extensión, de los límites caracterizan tanto al referente como al texto; en términos de Elena Altuna, "este recorrido por los límites no deja indemne al texto, que debe amoldarse a los varios discursos que entran en funcionamiento, intentado rodear a lo otro; de allí su permeabilidad genérica". ${ }^{13}$

Por otra parte, y como señala Beatriz Colombi, también es factible pensar el relato de viaje en tanto subgénero de la autobiografía o de la memoria. ${ }^{14}$ Ahora bien, en el caso de la crónica

12 Altuna 1996, 328.

${ }^{13}$ Ibidem, 331.

${ }^{14}$ En las notas a la introducción de Viaje intelectual, Beatriz Colombi menciona esta tesis y cita a Fussell, quien entrelaza memoria, viaje y autobiografía y subraya el encuentro con lo distante y el reclamo de una "validez literal" para lo narrado, que diferenciarían este relato de la novela, por ejemplo (Colombi 2004, 22). 
que nos ocupa, más que un subgénero podríamos hablar de un marco y una serie de herramientas formales que le permiten al cronista armar su texto, ya que memoria y autobiografía no existían como tales en el siglo XvI. ${ }^{15}$ En el caso de Bernal Díaz, que sostiene su veracidad en su calidad de testigo de vista, lo protoautobiográfico y el relato de viaje deben ir, a la fuerza, estrechamente unidos. De este modo, el 'autobiógrafo' dibuja su propia imagen y le confiere cierto relieve; de acuerdo con su entorno "se constituye en testigo de sí mismo y toma a los demás como testigos de lo que su presencia tiene de irreemplazable". ${ }^{16}$ De hecho, Bernal Díaz reitera ese gesto de modo constante en el relato del viaje a las Hibueras, frente a un entorno entre natural y humano en el que se destaca por su inteligencia, valor y persistencia: ocurre que el viaje y sus 'pruebas' le son esenciales - y funcionales - a su enaltecimiento personal.

Aquellas zonas de la HV que pueden ser caracterizadas como relato de viaje contribuyen a ampliar estos límites y son respuesta a la revolución cultural del encuentro con el Nuevo Mundo, que impacta en las formas genéricas tradicionales. Exceden, por lo tanto, el mandato real o lo meramente administrativo, ya que la HV exhibe una enorme capacidad para trabajar con distintos géneros y marcos, raíz de su indefinición y también de su modernidad. Asimismo, el relato de viaje pone en escena cierta pulsión de la escritura, y la memoria y la reconstrucción de estos desplazamientos como tácticas de conformación de identidades. Pensar el viaje a las Hibueras en ese marco recupera cierta dimensión del placer de la escritura, la confianza en la letra y la experiencia. ${ }^{17}$

15 Al respecto, véase Gusdorf 1991, 9.

16 Ibidem, 10.

17 Sigo en este sentido las apreciaciones de Loreley El Jaber para los relatos de viaje de los siglos XVI y XVII (El Jaber 2004). 
La expedición a las Hibueras relatada por Bernal Díaz pone en escena la preeminencia del relato a partir de lo visto y lo vivido, exacerbando cansancios, fatigas, peligros y la enorme capacidad (colectiva) "de españoles excepcionales para soportar lo insoportable y seguir fieles a su designio, así sea éste insensatez y suponga el sufrimiento y la muerte de muchos, con tal de no rectificar la decisión inicial: cuestión de honor y señorío". ${ }^{18}$ Por lo tanto, ofrece al narrador la posibilidad de reforzar cierta identidad colectiva, definida esta vez en relación con las pruebas que se les presentan y con su lealtad al capitán. Esto no excluye, claro, la mirada piadosa sobre los miles de indígenas muertos en la expedición o sobre los padecimientos de hombres menos preparados - como los frailes que los acompañaban-, pero sirve para focalizar la mirada en los juicios y las capacidades de los soldados de Cortés, ya que las dotes de mando y la inteligencia del capitán son puestas en duda capítulo a capítulo y padecimiento a padecimiento, al tiempo que se engrandece la figura del soldado devenido cronista.

Por lo demás, aquello que define al viajero se vincula también con el ya referido debate sobre el conocimiento a partir de la experiencia sensible, sólo posibilitado por el viaje y la migrancia. ${ }^{19}$ Subyace aquí cierta "determinación o autodeterminación libresca", ${ }^{20}$ donde viaje y escritura se entrelazan, si

18 Martínez 1995, 272.

${ }^{19}$ Así lo explica María Christen Florencia en su trabajo "El viaje a las tinieblas. La expedición a las Hibueras según Bernal Díaz del Castillo", donde también cita a Miguel A. Guerin, quien define al viajero como aquel que "produce un texto en que se presenta a sí mismo como el que ha sufrido fatigas, ha corrido peligros y aún ha hecho erogaciones, con el objeto de poder ver para informarse, de poder interrogar para comprender lo visto y de poder ejercitar su espíritu crítico para discernir la verdad de lo maravilloso. [...] El texto del relato de viaje debe evidenciar que los conocimientos del mundo que refiere se adquirieron inicialmente mediante la experiencia sensible, aunque no provengan exclusivamente de ella" (citado en Christen Florencia 2004, 11 y tomado también de Guerin 1992, 5).

${ }^{20}$ El Jaber 2004. 
bien no como génesis o decisión previa, sí en tanto conclusión y recompensa, probanza de méritos y memorial.

\subsection{El sujeto}

Todo relato de viaje puede ser interpelado en función de su enunciación: ¿quién habla, para quién? ¿Cómo se construye la identidad (la autofiguración) del enunciador y las siluetas de otros personajes? En suma, ¿cómo es este viajero que suscribe, con su memoria corporal, las imágenes de un territorio desconocido? El viaje (la migrancia, la exploración, la conquista y fundación de nuevas poblaciones) en tanto ataque a la identidad propia, unívoca o monolítica, es una prueba para las capacidades de aprehensión y comprensión de quien viaja y cuenta - aun cuando la narración posterior, gracias a la mediatización de la memoria entendida como trabajo, ${ }^{21}$ pueda ser pensada en términos de reordenamiento que permite la comprensión y la estabilidad de aquello que hubiera quedado en suspenso- - Si toda identidad se define frente a la alteridad, el viaje a las Hibueras habilita distintos modos de la autorrepresentación, a partir de los cuales los sujetos se definen no tanto frente al otro - mucho menos distante ahora que la percepción ha sido atravesada por la experiencia de la conquista del centro de México- como frente a la naturaleza y a lo desconocido. ${ }^{22}$

Aquello que delinea las expectativas y el imaginario de los conquistadores-expedicionarios es la cultura occidental —con

21 Jelin 2002.

22 Como indica María Christen Florencia: "En esta expedición [el grupo de menos relieve] es el de los indios. Aunque sus acciones determinen parte de los sufrimientos de los españoles, la mayor parte de las veces no son decisivas" (Christen Florencia 2004, 22). En efecto, fundamentales en la primera parte de la HV, hasta la caída de México Tenochtitlan, en el viaje a las Hibueras los indígenas se desdibujan, en comparación con las referencias al espacio casi no ocupan lugar en el relato, y sólo ingresan en términos de su funcionalidad. 
la particular modulación que en España adquiere la reconquista y el peso de lo religioso en la concepción de mundo-, y las vivencias previas en el centro de México, tiempos de enormes trabajos pero también de maravilla ante civilizaciones desconocidas. En este sentido, los preparativos del viaje a las $\mathrm{Hi}-$ bueras son majestuosos y desproporcionados: aquí se percibe ya la distancia entre la exhibición de poder y la realidad del espacio que deben enfrentar — de algún modo, entre el deseo y lo real, engaño de los sentidos que vicia este emprendimiento desde sus inicios-. ${ }^{23}$

En el capítulo CLXXIII de la HV (que abre esta narración), el cronista presenta a quien será uno de los ejes de la expedición, Cristóbal de Olid, "personaje maldito, [que] siempre está más allá y nunca parece poder alcanzarse", ${ }^{24}$ explicando su traición, también con el objeto de justificar las acciones posteriores de Cortés. En este capítulo, el narrador-viajero opera sobre el orden de la historia, puesto que adelanta la muerte de Olid a manos de los amigos de Cortés, dato que los expedicionarios sólo conocieron un año y medio después de iniciado el trayecto. Este manejo de la materia narrada agudiza la tragedia de lo que se referirá en los capítulos inmediatamente posteriores, donde se detallan los padecimientos de un grupo que había partido en busca de un fantasma, "que ya era humo, cenizas, hueso". ${ }^{25}$ De algún modo, Cristóbal de Olid es sombra, móvil y motor del viaje, tanto más potente cuanto más inasible o escurridizo. Símbolo del arrojo que hizo posible la conquista de México, como también de las intrigas y luchas de poder que

${ }^{23}$ En sus notas a la edición de las Cartas de Relación de Hernán Cortés, Mario Hernández Sánchez Barba hace notar que este fasto se debe, en verdad, a la calidad del capitán como representante del rey. Empero, puesto que este trabajo analiza textualidades, no puede dejar de notarse el acento puesto en la descripción de preparativos y atavíos, y la contraposición fragante —e incluso dolorosa - con el resultado de la expedición.

${ }^{24}$ Christen Florencia 2004, 19.

25 Ibidem, 20. 
asfixian el derrotero cortesiano en el Nuevo Mundo, Olid representa el peligro y el pretexto, y su rebelión incita en Cortés — según la HV - el ansia de venganza, más aún en la medida en que su poder se ve amenazado. Esta imagen espectral nubla la vista del capitán y le impide ver la peligrosidad de lo que deja atrás —en la ciudad de México—, y que será otro de los motivos de su desgracia, una vez de regreso de las Hibueras.

En este marco, la puesta en escena del contexto de toma de decisiones marca una flexión en la definición del nosotros colectivo tal como venía presentándose en la $\mathrm{HV}$, en beneficio de un protagonismo aún mayor de Bernal Díaz - y de algunos de sus compañeros- Las temerarias decisiones no pueden sostenerse, claro, sólo en el cambiante ánimo de Cortés, ya que esto quitaría voz y voto a los soldados — particularidad que el narrador ha venido enfatizando en los ciento setenta y dos capítulos anteriores-. Por eso, las justifica aludiendo a cuestiones de lealtad, coraje y venganza, que dan cierta idea de lo caballeresco — siempre presente en la $\mathrm{HV}$ - y definen el honor de los conquistadores.

Bernal Díaz no deja de subrayar — en una enumeración que acentúa la hipérbole que define la expedición- el fasto y el lujo de la desmesurada comitiva de hasta tres mil indios, que incluía, claro, oficiales, tenientes, frailes; muchos "principales" indígenas, entre ellos Cuautéhmoc (Guatemuz para Bernal) - "porque quedase más pacífico y sin cabeceras de los mayores caciques"-; cazadores de halcones y hasta una "gran manada de puercos, que venía comiendo por el camino" — protagonistas de no pocas rencillas y resquemores cuando el hambre comenzó su asedio——. ${ }^{26}$ Si bien la enumeración es una estrategia habitual en las descripciones, con usos diferenciados de acuerdo con la intencionalidad del enunciador - representación de la mirada de quien mide, inventaría y evalúa

${ }^{26}$ Díaz del Castillo 2005, 633-634. 
futuras posesiones, y también construcción de una imagen de experticia-, en este caso funciona como panorama ajustado de cierto estado de cosas posterior a la toma de México-Tenochtitlan y, en su antitética colocación, como patético reverso del fracaso posterior. ${ }^{27}$

Empero, no podemos olvidar la propensión por el detalle que define la $\mathrm{HV}$, en tanto efecto de verosimilitud e historicidad ajustado a los cánones del relato de una experiencia sensible y, al mismo tiempo, en tanto autolegitimación del lugar autoral. ${ }^{28}$ Claro, esta sensibilidad a las cuestiones humanas permite un relato que completa, amplía y muchas veces polemiza con las cartas de Cortés y que, como señala José Luis Martínez, constituye una de las pocas fuentes directas acerca de la expedición. ${ }^{29}$ Apreciaciones como ésta tienen especiales resonancias cuando pensamos que este "discurso narrativo del fracaso" — para decirlo en términos de Beatriz Pastor- ${ }^{30}$ actualiza un desplazamiento del texto y de la autofiguración del sujeto que escribe porque recuerda, en el marco de una representación 'distinta' del espacio americano. En efecto, si desde los diarios de Colón la abrumadora naturaleza americana es un ingrediente ineludible del imaginario sobre el continente, el viaje a las Hibueras pondrá en primer plano la dificultad del enfrentamiento con el medio, que a cada paso se presenta hostil e inmisericorde, modificando las connotaciones del par naturaleza-cultura, que tan bien había funcionado para describir las acciones llevadas a cabo en el centro de México.

27 Este tipo de usos de la descripción y la enumeración son analizados por John Tallmadge en "Voyaging and the Literary Imagination".

${ }^{28}$ Bernal Díaz encara la escritura a partir de la digresión y el detalle, en coincidencia con ciertas características de la novela moderna — tal como señala María E. Meyer respecto del Quijote-, es decir, con nuevos modos de escribir y de concebir el relato de la experiencia pasada o el mundo ficcional, en cada caso. Por eso, "las Hibueras son a Bernal lo que la cueva de Montesinos a don Quijote: una arriesgada incursión narratológica en terreno desconocido" (Mayer 1994, 102).

29 Martínez 1995, 273.

${ }^{30}$ Pastor 1983, 8. 
Por no quebrar el hilo de lo uno por decir lo otro, acordé de seguir nuestro trabajosísimo camino. Bernal Díaz del Castillo, HV, 1995, cLXXv.

El relato del viaje a las Hibueras escenifica la confrontación entre las concepciones del espacio en abstracto, las cartografías renacentistas - según Henri Lefevre, fundamentales en la constitución de la modernidad - y la experiencia de la sobrecogedora diversidad de la geografía americana. ${ }^{31}$ En dicho cruce, los capítulos referidos presentan numerosos desvíos y escenas que se suceden sin orden causal. El comienzo, la partida entendida como acto inaugural asumido por todo viajero - y también como inicio de la escritura-, condensa las características del relato posterior, contrarias punto por punto a la norma letrada respecto de la escritura de la historia - brevedad, concisión, "la particularité ou la généralité du recit, la naiveté du style", entre otras—. ${ }^{32}$ Así, el orden del discurso parecería basarse en cierto desorden de la remembranza antes que en la lógica sintagmática a la que la escritura somete al recuerdo.

La descripción del espacio configura un personaje más, de características humanas: crueldad, inmisericordia, resistencia, capacidad para sorprender, constante metamorfosis. A lo largo de toda la expedición se establece una guerra abierta entre el hombre y el medio, de la cual sólo estos "españoles excepcionales" pueden salir con vida. ${ }^{33}$ Claro, un verdadero soldado español no se rendiría sin pelear y, ante la violencia de los elementos y el desaliento de Cortés, la imagen de Bernal se enaltece

31 Lefevre 1983.

32 Doiron 1988, 88.

33 Picón Salas 1985, 59. 
hasta convertirse en guía y salvador de los escasos supervivientes. Es él, junto con otros "valientes" —así los llama-, quien consigue alimentos para todos en varias oportunidades, e incluso quien se enfrenta al capitán — que da muestras entonces de sus nunca del todo olvidadas dotes diplomáticasreclamándole por los puercos comidos a espaldas del resto de la expedición.

Por otra parte, este versátil espacio cuenta con la ventaja de su extensión y capacidad de mutación: de la selva se pasa al pantano, a la sabana, a los esteros o al mar. Cuando los hombres comienzan a conocer el terreno y descubrir sus debilidades, la naturaleza cambia y los enfrenta a nuevos retos. La naturaleza obliga al despojamiento - cuando no arranca, directamente, los múltiples bienes inútiles que portan, entre ellos, la vajilla de oro y plata - y empuja hacia lo primigenio y salvaje, representado, en el límite, por la antropofagia cometida por los indígenas que los acompañan, y referida en el capítulo CLXXVI.

En este marco, el viaje a las Hibueras se va configurando como un desplazamiento sin caminos ni recorridos trazados previamente, vírgenes del orden exploratorio occidental, donde la naturaleza se resiste a la lógica extraña de los expedicionarios, y esconde o confunde sus señales. De este modo, se perfila — no sin dificultades - un movimiento en el que el territorio presenta engañosos índices, que insinúan la presencia de su objeto para, por fin, mostrar su ausencia: no hay tal camino; se han desplazado en círculos; detrás de la selva sólo hay más selva o sabana o mar — siempre, muerte-.

Este viaje es también un derrotero que transforma el paisaje, escandido de cadáveres de indios y españoles que mueren en ríos, cenagales, pantanos, consumidos por la sed, la fatiga y las enfermedades. Con insistencia, los expedicionarios van dejando sus marcas en los árboles (donde escriben "Por aquí pasó Cortés en tal tiempo [para que] si viniesen otras personas 
en nuestra busca, supiesen cómo íbamos adelante", ${ }^{34}$ en un gesto de cultura inscrito - tatuado- en la naturaleza. Más aún, este relato presenta con peculiar énfasis un protagonista central de la conquista: el cuerpo. Maltratado, dolido, cansado, enfermo, comido, quemado, cuerpo-cadáver y cuerpo-deshecho. También la dimensión más humana y brutal del desplazamiento: a pie, donde "el cuerpo padece y mensura el camino. [...] La naturaleza, entonces, dista de ser dominada, se está, como por un momento, fuera de la cultura". ${ }^{35}$ Porque se depende por completo del propio cuerpo $-\mathrm{y}$, muchas veces, se está sujeto o atrapado en él—, sólo es opción viable la resistencia y el movimiento permanente. Esta necesidad configura un viaje tensionado entre la orden de avanzar siempre, tal como insta el capitán, y el impulso del retorno. No obstante, a medida que se internan en el territorio, no hay - literalmentevuelta atrás: la selva se cierra tras ellos como pesada pared verde detrás de la cual acecha la muerte.

En este "laberinto fluvial", ${ }^{36}$ el territorio se ve transformado por los supervivientes gracias a un 'prodigio de ingeniería humana' que también funciona (en la crónica) como medida del tiempo: los puentes. Parte central del relato del desplazamiento, éstos exhiben la concepción occidental aplicada al espacio americano, así como un saber ajeno que se adapta para domesticar lo salvaje, en su desmesura. Serán símbolo de esfuerzo y valor, y perdurarán por años, conocidos como "los puentes de Cortés" - metonimia que olvida al colectivo que los hizo posibles-. ${ }^{37}$ Asimismo, son metáfora perfecta del relato que los convoca: organización y aprehensión de un espacio otro en el que se dejan marcas perdurables; nominación y posesión; mediación entre dos extremos sólo distinguibles por la

\footnotetext{
${ }^{34}$ Díaz del Castillo 2005, 642.

35 Monteleone 1998, 243.

36 Martínez 1995, 273.

37 Díaz del Castillo 2005, 641.
} 
contingencia del conocimiento o el desconocimiento, bajo los cuales anida el peligro. El puente y el agua - turbia, oscura, cenagosa, amenazante, violenta- son el par que describe buena parte de la travesía, en una tensión que no parece tener fin para los agotados constructores. $\mathrm{Si}$ "no hay viaje sin relato", 38 aquí la escritura intenta funcionar también como elemento de orden para el desorden del extravío, y mide en jornadas, puentes, indios, poblaciones, la soterrada magnitud de la tragedia.

Por otra parte, si lo dicho y lo elidido definen la naturaleza de todo texto y, con mayor énfasis aún, el natural proceso de selección y ordenamiento que el relato de un viaje pasado impone, detectar estos silencios aquí permite develar los trabajos de la memoria y presentar hipótesis sobre posibles intencionalidades así inscritas. En efecto, frente al relato de las numerosas vicisitudes y de las triunfantes llegadas de Bernal Díaz, el lector no deja de preguntarse, por ejemplo, hacia dónde se dirige el soldado en busca de comida, ya que el texto sólo narra los momentos de espera, desaliento y desesperación... Hay allí una curiosa elisión que esconde ciertos saberes y tácticas que engrandecerían aún más la imagen del soldado. No puede leerse en este tramo una improbable modestia por parte del narrador-protagonista sino, antes bien, cierta consciente elección en términos de relevancia y de configuración identitaria. Para decirlo con claridad: si la identidad se define de modo relacional, esta selección textual muestra que la imagen del narrador protagonista se articula por diferencia, en el ámbito de sus congéneres y compañeros, y en función de un antagonista claro: Cortés. Si bien Bernal Díaz nunca se atreve a tanto como a equipararse al capitán — su admiración y su experiencia de soldado no se lo admitirían-, es en el viaje a las Hibueras donde estas figuras más se acercan y se enfrentan, en

38 Monteleone 1998, 9. 
la medida en que la imagen del soldado crece y la del capitán decrece, atribulado por los padecimientos y las pésimas noticias provenientes de México.

El texto escenifica una tensión entre el aquí de la expedición y el allá de México que limita la narración, asediada por la imposibilidad sintagmática de aludir a cuestiones que ocurren en forma paralela. Por eso, la estructura del relato intercala capítulos con noticias de la ciudad o de otras expediciones, que tienen un enorme impacto en Cortés y sus hombres, y que influyen en el derrotero trazado por la cada vez más reducida comitiva. Asimismo, acentúa la imagen de un capitán siempre incómodo, a caballo entre dos tiempos, dos espacios, y múltiples conspiraciones y problemas, donde la duda y la vacilación serán las características que lo identifiquen.

\section{Comienzos y finales}

Al inicio del apartado anterior hicimos referencia a las Hibueras como espacio de expiación y compulsión, connotaciones leídas en la conflictiva figuración de Cortés que el relato propone. Si, como señala José Luis Martínez, en las cartas al rey "Hernán Cortés apenas deja traslucir su frustración, su tristeza y sus propios quebrantos", éstos son recogidos y minuciosamente anotados por Bernal Díaz del Castillo, "sensible a las cosas humanas". 39

Interesa retomar estas consideraciones en torno a Cortés porque permiten pensar que el enfrentamiento con los propios límites ante el otro lleva a un alejamiento (espacial y temporal) que es también un repliegue hacia ciertas ideas de lealtad, justicia, orden, incluso escala de mando, y la puesta en escena de una ficción de poder que el propio territorio se encarga de

${ }^{39}$ Martínez 1995, 272-273. 
despedazar. Si, al principio, el narrador no se cansa de detallar los fastuosos recibimientos en todas las poblaciones, tampoco deja de apuntar los consejos brindados por "todos los conquistadores viejos amigos de Cortés que quedavan en México", 40 quienes mucho temían que, con su partida, "se alzará toda Nueva España", ${ }^{41}$ e incluso los malos agüeros que parecieran marcar la partida. A posteriori, la memoria rescata y organiza, en términos indiciales, informaciones fragmentarias que, reunidas de este modo, por acumulación y enumeración en un solo capítulo (el CLXXIV), funcionan como enunciados anticipatorios y también como justificado lamento por un fracaso que se revela, en la lógica del sintagma, innecesario en tanto previsible. Es más, esta acumulación de noticias y consejos contrarios al viaje delinea una imagen de Cortés muy distinta a la que la HV nos tenía acostumbrados: el capitán está sordo, no escucha, se abstrae en sus pensamientos y también se arrepiente de haber enviado a Francisco de Las Casas en lugar de "haber ido él en persona"; 42 taciturna introspección de Cortés que aumenta y se agudiza a medida que los acecha la "mala fortuna". ${ }^{4}$

De este modo, el viaje a las Hibueras obliga a volver a medir las posibilidades de la voluntad frente al territorio y es, también, una experiencia que reorienta la mirada sobre el otro, el yo y la propia fe. Quien emprende el regreso es un sujeto "flaco y mal dispuesto y quebrantado de la mar y muy temeroso de ir a la Nueva España, por temor no le prendiese el factor", ${ }^{4}$ un capitán desconocido para los lectores de la HV. Este miedo, que el narrador subraya en varias ocasiones, lo enfrenta finalmente con sus soldados, en un momento en que acciones y señales cambian de sentido. Las jerarquías se subvierten, los

\footnotetext{
40 Díaz del Castillo 2005, 634.

41 Ibidem, 634.

42 Ibidem, 633.

43 Ibidem, 635.

${ }^{4}$ Ibidem, 665.
} 
ánimos se encienden, y el texto se llena de referencias a las cartas cruzadas entre soldados y capitán, con la mediación —bien intencionada pero no siempre eficaz - de Sandoval, encargado de persuadir a ambos bandos. A medida que el narrador se deja llevar por el reclamo, la queja y hasta la ira respecto de las palabras de Cortés, aumenta el desorden y la digresión en el texto, ya que éste, además, debe dar cuenta de sucesos que ocurren en tres lugares en forma simultánea.

El retorno es, para Cortés, la resistencia al regreso y, para sus soldados, el deseo de volver a la quimérica ciudad de México, donde esperan recuperar haciendas, indios, incluso mujeres e hijos. Ocurre que la ciudad ha dejado de ser el "paraíso perdido" para el capitán, quien parece ser el único que percibe con claridad las complicaciones y los peligros que allí los acechan. Aún más allá de las intenciones del narrador (que subraya en forma constante la aparente sinrazón de Cortés, su temor frente a los enemigos en la urbe), el texto despliega la complejidad del nuevo ordenamiento postconquista, donde los conquistadores 'de la primera hora' tienen cada vez menos espacio. En cambio, los soldados, incapaces de comprender esto, proyectan sobre el capitán — no sin razón— el cansancio y el fracaso. Empero, la solución alternativa, que avizoran como una entrada triunfal a Tenochtitlan, ya es solo una utopía.

Entonces, Cortés envía a un criado suyo, Martín de Dorantes, con cartas y poderes "para Pedro de Alvarado y Francisco de las Casas, si obieren buelto a México, para que fuesen governadores de la Nueva España, hasta que Cortés fuese". ${ }^{45}$ Para hacerlo, organiza una estratagema que utiliza el disfraz y saca provecho de los cambios que el trayecto a las Hibueras ha producido en los cuerpos de los sufrientes expedicionarios. Cuenta Bernal Díaz:

45 Ibidem, 687. 
Se disfrazó Martín de Dorantes porque no lo conociecen, y quitó sus vestidos y tomó otros como de labrador, porque así le fue mandado por Cortés, y aún llevó echos los bestidos desde entonzes. Y con todas sus cartas y poderes bien ampliados y liados en el cuerpo de manera que no hiciezen bulto, iva a más a andar por su camino a pie, que era suelto peón; y cuando llegaba a los pueblos de indios que abía españoles, metíase entre los indios por no tener pláticas ni le conosciesen, e ya que no podía menos de tratar con españoles no le podían conocer, porque ya había dos años e tres meses que salimos de México y le abían crecido las barvas. ${ }^{46}$

El criado se confunde con el indio; el enemigo es, ahora, el español; los distintos bandos se definen cada vez más y las consecuencias de las malas decisiones —abandonar México, ceder el poder a personajes inescrupulosos - precipitan la caída. No obstante, lo más destacable en esta cita es la puesta en escena de una nueva realidad que se ha vuelto contra los intereses de los conquistadores viejos pero que el capitán, no recuperado - aunque, al menos, 'de regreso'-, sabe leer e intenta manipular, como en los inicios de la conquista. Esta distancia marca también la diferencia entre Cortés y sus soldados respecto de la capacidad de comprensión de la situación que muestran uno y otros e, incluso, de la facultad de leer y usar desviadamente ${ }^{47}$ las consecuencias de la expedición —como la distancia, puesto que Cortés está en Trujillo, o la confusión producida por la defectuosa comunicación; también las marcas de estos años de exploración y vagabundeo en el cuerpo de Dorantes - para intentar torcer la situación a su favor.

De este modo se configura un viaje quimérico — definido por el desajuste: de medios, motivos, preparativos, itinerarios-

46 Ibidem, 688.

${ }^{47}$ Al respecto, seguimos las consideraciones de Michel de Certeau sobre el lector como "cazador furtivo" y los modos de las lecturas desviadas, incluidas en La invención de lo cotidiano. 1: Artes de hacer. 
y un retorno imposible. Las Hibueras determinan también el fin del viaje para los conquistadores-exploradores: a su regreso, Cortés se dedicará a litigar, será sometido a juicio de residencia y cerrará con estos relatos la Quinta Carta al rey. Los supervivientes buscarán honores, encomiendas o tan sólo el retorno a los hogares. Como ya señaláramos, en este derrotero también se ha deslizado el sujeto, tal como lo muestran las cartas de Cortés leídas en sucesión, y como el mismo Bernal Díaz lo afirma.

Ocurre que, gestado en las ansias de gloria y venganza, este viaje escenifica un profundo desencuentro: entre Cortés y sus 'vengadores' —quienes ya han matado a Cristóbal de Olid cuando la expedición inicia su camino-; entre Cortés y sus hombres; entre los soldados mismos, diferenciados por sus pertenencias territoriales en la patria de origen. De modo más general, también presenta el desencuentro entre el hombre y su deseo: si al principio se anhela el poder y la gloria, luego sólo se busca agua, comida, o la posibilidad (poco probable) de regresar con vida a lo que se ha dejado atrás: encomiendas, casas, familias — tal como no se cansa de señalar Bernal Díaz-. Este viaje actualiza la ambición del retorno a la ciudad (para siempre) perdida, donde todo se desarrollará ahora según una lógica que les es extraña, que ni siquiera Cortés — con su proverbial astucia - puede finalmente desarticular.

\section{REFERENCIAS}

Altuna, Elena, 2004. "Relaciones de viajes y viajeros coloniales por las Américas", Revista de Crítica Literaria Latinoamericana, año xxx, 60, Lima-Hannover, 2do. semestre, 1-19.

_, 1998. "El relato de viaje como texto de frontera", en Actas de las III Jornadas Nacionales de Literatura Comparada, Córdoba, 22 al 24 de agosto de 1996, 325-334.

Christen Florencia, María, 2004. "El viaje a las tinieblas. La expedición a las Hibueras según Bernal Díaz del Castillo”, en Luz 
Elena Zamudio (coord.), Espacio, viajes y viajeros, México, Aldus / UAM, 19-42.

Colombi, Beatriz, 2004. Viaje intelectual. Migraciones y desplazamientos en América Latina (1880-1915), Rosario, Beatriz Viterbo.

CoRTés, Hernán, 1985. Cartas de Relación, ed. Mario Hernández Sánchez Barba, Madrid, Historia 16.

De Certeau, Michel, 2000. La invención de lo cotidiano. 1. Artes de hacer, [1991], versión corregida y aumentada Luce Girad, trad. Alejandro Pescador, México, Universidad Iberoamericana.

Díaz del CAstillo, Bernal, 2005. Historia verdadera de la conquista de la Nueva España (Manuscrito Guatemala), edición crítica de José Antonio Barbón Rodríguez, México, El Colegio de México, Universidad Nacional Autónoma de México, Servicio Alemán de Intercambio Académico, Agencia Española de Cooperación Internacional.

Dorron, Normand, 1988. "L'art de voyager”, Poétique, 73, 83-107.

EL JABER, Loreley, 2004. "Viaje, mirada y experiencia. Hacia una teoría sobre el relato de viaje" (mimeo, por una gentileza de la autora).

Foucault, Michel, 2000. Arqueología del saber, [1970], trad. Aurelio Garzón del Camino, Buenos Aires, Siglo XXI Editores.

GuERIN, Miguel A., 1992. "El relato de viaje americano y la redefinición sociocultural de la ecumene europea", Dispositio, XVII, 42, $1-19$.

GuSDORF, Georges, 1991. "Condiciones y límites de la autobiografía”, Anthropos, suplemento "Autobiografía”, 29, 9-18.

JeLIN, Elizabeth, 2002. Los trabajos de la memoria, Buenos Aires, Nueva Visión.

Lefevre, Henri, 1983. La revolución urbana, [1970], trad. Mario Nolla, Madrid, Alianza.

LÓPEZ DE MARISCAL, Blanca, 2004. Relatos y relaciones de viaje al Nuevo Mundo en el siglo XVI, México, Ediciones Polifemo / Tecnológico de Monterrey.

Martínez, José Luis, 1995. Hernán Cortés, México, FCE.

MAYer, María E., 1994. "El detalle de una 'historia verdadera', Don Quijote y Bernal Díaz", Bulletin of the Cervantes Society of America, 14:2, 93-118. 
Mignolo, Walter D., 1981. "El metatexto historiográfico y la historiografía indiana", Modern Language Notes, 96, 358-402.

Monteleone, Jorge, 1998. El relato de viaje. De Sarmiento a Umberto Eco, Buenos Aires, El Ateneo.

Pastor, Beatriz, 1983. Discurso narrativo de la conquista de América, La Habana, Casa de las Américas.

Picón Salas, Mariano, 1985. De la conquista a la independencia, [1944], México, FCE.

Pierini, Margarita, 1994. "La mirada y el discurso: la literatura de viajes", en Ana Pizarro (org.), América Latina. Palabra, literatura y cultura, Sao Paulo, Editora Da Unicamp, II, 161-183.

Pratt, Mary Louise, 1997. Ojos imperiales, [1992], Buenos Aires, UNQUI.

SAID, Edward, 2001. Fuera de lugar, trad. Xavier Calvo, [2000], Barcelona, Grijalbo.

—, 1995. Orientalism, [1978], London, Penguin.

TAllmadge, John, 1979. "Voyaging and the Literary Imagination", Exploration: Journal of the MLA Special Session on the Literature of Exploration and Travel, VII, 1-16. 